\title{
Clinical profile of chronic kidney disease of unknown origin in patients of Yavatmal district, Maharashtra, India
}

\author{
Dhananjay Ookalkar $^{{ }^{\oplus}}$, Ashwini Ookalkar $^{1}$, V.L. Gupta $^{{ }^{\oplus}}$, Manish R Balwani $^{2^{*}}$
}

\begin{abstract}
We present a case series of patients with chronic kidney disease of unknown etiology (CKDu) coming from a well-defined geographic area, Yavatmal, district of Maharashtra, in central India. These patients presented with advanced renal failure, variable proteinuria, and bilateral hyperechoic kidneys, largely normotensive and belonged to poor economic class from agricultural communities. The study highlights the need for large epidemiological survey in Yavatmal region to detect patients with CKDu and investigate the possible etiology.

Keywords: Chronic kidney disease of unknown origin, Glomerular filtration rate, Proteinuria

Citation: Ookalkar D, Ookalkar A, Gupta VL, Balwani MR. Clinical profile of chronic kidney disease of unknown origin in patients of Yavatmal district, Maharashtra, India. J Renal Endocrinol. 2021;7:e01. doi: 10.34172/jre.2021.01.

Copyright $\odot 2021$ The Author(s); Published by Nickan Research Institute. This is an open-access article distributed under the terms of the Creative Commons Attribution License (http://creativecommons.org/licenses/by/4.0), which permits unrestricted use, distribution, and reproduction in any medium, provided the original work is properly cited.
\end{abstract}

\section{Introduction}

Chronic kidney disease of unknown origin $(\mathrm{CKDu})$ has been reported from many hotspots across the globe from central America, Egypt, Srilanka, and coastal India (1). In the first report of Indian CKD Registry, CKDu is the cause of CKD in $18 \%$ of the population (2). The study of Global dimensions and perspectives of CKD by Jha et al have shown that the poorest populations are at the highest risk (3).

\section{Patients and Methods}

It is a single center retrospective study carried out at Ashwini Kidney and Dialysis Centre Pvt Ltd, Nagpur, India where medical data of all patients diagnosed to have $\mathrm{CKDu}$ were retrospectively reviewed. All patients from Yavatmal district reporting between April 2018 till June 2019 were identified. Total 2365 patients were seen during this period. 357 patients were from yavatmal district. Out of these, 19 patients fulfilled all the criteria as per the definition of probable and confirmed CKDu as given by the WHO group in Srilanka (4). Estimated glomerular filtration rate (eGFR) was calculated using CKD EPI (Chronic Kidney Disease Epidemiology Collaboration equation) formula. The eGFR and serum creatinine were estimated at intervals minimum 12 weeks apart. The KDIGO guidelines 2012 was followed for the staging (5). The inclusion criteria for probable CKDu were eGFR $<60$ $\mathrm{mL} / \mathrm{min}$ with at least two eGFR readings more than 12 weeks apart or proteinuria more than $150 \mathrm{mg}$ /day or urine protein creatinine ratio of more than 0.15 . Demographic, clinical, biochemical data were collected and analyzed. The study was conducted according to the Helsinki Declaration and informed consent was obtained from all participants. The study was approved by Institutional Ethics Committee, DMIMS, Wardha, India.

Results

\section{Sociodemographic profile}

The mean age group was $55.42 \pm 10.5$ years with majority of the patients between the age group of 40 to 70 years (84.21\%). There was a progressive increase in the number of patients for each decade beyond 30 years up to 70 years of age. CKDu was seen more in males as compared to females. Most of the affected patients belonged to Banjara community $(73.69 \%)$ and remaining five patients (26.31\%) were from other communities. The subjects were predominantly farm labourers $(63.15 \%)$ and rest (36.84\%) were engaged in non-farming activities. The subject population has well water as the source of drinking water $(100 \%)$ (Table 1$)$.

\section{Clinical and biochemical profile}

At the time of presentation, mean serum creatinine was 3.8 $\pm 2.4 \mathrm{mg} / \mathrm{dL}$ and the mean eGFR was $23.85 \pm 14.24 \mathrm{~mL} /$ $\min / 1.73 \mathrm{~m}^{2}$. As per KDIGO staging, 5 patients presented $(26.31 \%)$ with stage 3,7 patients $(36.84 \%)$ with stage 4 and 
Table 1. Demographic, social variables of patients $(n=19)$

\begin{tabular}{lll}
\hline Age & Range $(37-73 y)$ & Mean \pm SD $(55.42 y \pm 10.5)$ \\
\hline $\begin{array}{l}\text { Sex } \\
\text { distribution }\end{array}$ & Males, $15(78.95 \%)$ & Females, $4(21.05 \%)$ \\
$\begin{array}{l}\text { Community } \\
\text { Occupation }\end{array}$ & Banjara, $14(73.69 \%)$ & Fon-Banjara, $5(26.31 \%)$ \\
$\begin{array}{l}\text { Source of labourers, } 12(63.15 \%) \\
\text { water }\end{array}$ & Well water, $19(100 \%)$ & Others 7 (36.84\%) \\
\hline
\end{tabular}

7 patients (36.84\%) with stage 5 CKD.

There were 11 patients (57.89\%) with less than $1 \mathrm{~g} / \mathrm{d}$ proteinuria and $8(42.10 \%)$ with proteinuria more than 1 $\mathrm{g} / \mathrm{d}$. Mean proteinuria was $0.93 \pm 0.35 \mathrm{~g} / \mathrm{d}$.

14 patients were normotensive while 5 patients were hypertensive. Mean systolic and diastolic blood pressure was $116.53 \pm 18.67$ and $77.27 \pm 12.48 \mathrm{~mm} \mathrm{Hg}$ respectively. Out of the 5 hypertensive patients, single drug therapy (80\%) was sufficient to control blood pressure while one patient required two drugs. None of the patients included in study had hypertension for more than 5 years duration. Mean hemoglobin was $11.04 \pm 1.75 \mathrm{~g} / \mathrm{dL}$. Mean serum sodium was $135 \pm 3.33 \mathrm{meq} / \mathrm{L}$ and the mean serum potassium was $4.6 \pm 0.7 \mathrm{meq} / \mathrm{L}$ (Table 2 ).

Mean eGFR in first reading data set was $23.85 \pm 14.24$ (SD) $\mathrm{mL} / \mathrm{min} / 1.73 \mathrm{~m}^{2}$. Mean eGFR in second reading data set after a gap of three months was $21.62 \pm 9.35$ (SD) $\mathrm{mL} / \mathrm{min} / 1.73 \mathrm{~m}^{2}$. The 2003 Weissgerber Paired Data Scatterplot table shows difference in the two sets of readings, majority of which lie below the mean. Only four patients showed increase in eGFR but this was still below $60 \mathrm{~mL} / \mathrm{min} / 1.73 \mathrm{~m}^{2}$.

\section{Histopathology}

One patient underwent a kidney biopsy. Histopathological features showed 7 glomeruli of which 5 were globally sclerosed and the remaining two were normal by light microscopy. Foci of tubular atrophy and interstitial fibrosis (40\%) were seen. Widespread flattening and loss of brush border of proximal tubules was noted. The interstitium showed diffuse mononuclear cell inflammatory infiltrate with few eosinophils. The blood vessels were normal. The

Table 2. Clinical and Biochemical characteristics of subject population in the Yavatmal region

\begin{tabular}{llll}
\hline Parameters & Mean \pm SD & Min & Max \\
\hline Serum creatinine $(\mathrm{mg} / \mathrm{dL})$ & $3.8 \pm 2.4$ & 1.3 & 8.0 \\
eGFR $\left(\mathrm{mL} / \mathrm{min} / 1.73 \mathrm{~m}^{2}\right)$ & $23.85 \pm 14.24$ & 7 & 58 \\
Systolic BP $(\mathrm{mm} \mathrm{Hg})$ & $116.53 \pm 18.67$ & 102 & 146 \\
Diastolic BP $(\mathrm{mm} \mathrm{Hg})$ & $77.27 \pm 12.48$ & 65 & 101 \\
Urine protein/creatinine ratio & $0.93 \pm 0.35$ & 0.38 & 1.59 \\
Haemoglobin $(\mathrm{gm} / \mathrm{dL})$ & $11.04 \pm 1.75$ & 8.8 & 14.1 \\
Serum sodium $(\mathrm{mEq} / \mathrm{L})$ & $135 \pm 3.33$ & 130 & 139 \\
Serum potassium $(\mathrm{mEq} / \mathrm{L})$ & $4.6 \pm 0.7$ & 3.2 & 5.4 \\
\hline
\end{tabular}

Implication for health policy/practice/research/ medical education

The study highlights the need for large epidemiological survey in Central India region to detect patients with CKDu and investigate the possible underlying etiologies.

biopsy was negative for immunofluorescence deposits. Kidney biopsy could not be performed in majority of the patients as kidney size was already small, or there were logistic issues.

\section{Discussion}

The Yavatmal district lies in the southwestern part of the Wardha-Penganga-Wainganga plain. The District lies between 19o 26' and 20o 42' north latitudes and 77o 18 ' and 79o 9' east longitudes. The District has an area of $13,582 \mathrm{~km}^{2}$, and a population of $27,72,348$ persons according to 2011 Census carried out by government of India. Most of the people of this district are engaged in agricultural activities. As per 2011 census, $24.59 \%$ of the total workers are engaged as cultivators and $54.55 \%$ of the total workers are engaged as agricultural labourers in the district. Together it constitutes $79.14 \%$ of the total workers of the district (6).

They are exposed to various agrochemicals and extreme heat during their work. In this case series of a single specialty tertiary centre, there is a predominance of males amongst the affected (78.94\%). This may be due to the fact that agricultural labourers and farmers are predominantly males. They are exposed to extreme heat while working due to which they have excessive sweating and continuous work without necessary water intake may lead to repeated dehydration. Such frequent dehydration episodes may cause subtle kidney injury which may go undetected. In a similar finding, young males were predominantly affected in the study on endemic nephropathy around the world (7). Author suggests that such hard working population must be made aware of importance of frequent hydration while working in such climatic conditions.

The age group in our study is nearly similar to the findings of Uddanam study where mean age of the subjects was $43.2 \pm 14.2$ years (range: $18-98$ ). However, in their study $44.3 \%$ were men and $55.7 \%$ were women (8). Only five of the 19 patients had hypertension, and were on antihypertensive medications. All the patients had varying degrees of proteinuria, measured by the urine protein creatinine ratio but majority had proteinuria less than 1 gm per day. In a similar study in central America, there was little or no proteinuria (9). The lack of hypertension and proteinuria less than one gm per day in majority of our patients despite advanced CKD points possibly to tubulointerstitial pathology.

The article on global epidemic of CKDu (10) expresses concerns about the Tatapudi's study (8) which does not 
have prevalence data as there are no repeat measurements of serum creatinine. Also, the Tatapudi's study does not address "long standing hypertension". Our study has taken only the patients with repeat serum creatinine measurements at 3 months.

Hyponatremia was seen in six patients. Again euvolemic hyponatremia points towards the tubular pathology. Renal biopsy may help in arriving at anatomical etiology for which biopsy needs to be performed in earlier stages of CKDu. The kidney biopsy finding in our patient is consistent with $\mathrm{CKDu}$ biopsy findings compared in the study on global dimension of CKDu (11).

This case series although small in number and being a single centre experience, highlights the need for large epidemiological study in Yavatmal and adjoining districts. There is also need of CKDu registry in this area. This will help in identifying the geographic distribution of CKDu. Many suspected CKDu patients did not come for a follow up visit. Therefore many suspected CKDu patients could not be included as probable and CKDu patients in this study. This calls for better nephrology services in Yavatmal and adjoining areas.

\section{Conclusion}

Our limited sample study shows that CKDu affects mainly agricultural communities consuming well water. Although the total number of patients in this area must be many times more than the numbers reported here, only a registry and epidemiological study with protocol-based workup will help in bringing the true CKDu numbers to public notice.

\section{Limitations of the study}

Small sample size results could not be generalized.

\section{Authors' contribution}

$\mathrm{DO}, \mathrm{AO} \& \mathrm{VG}$ were the principal investigators of the study. DO, AO \& VG were included in preparing the concept and design. DO and $\mathrm{AO}$ revised the manuscript and critically evaluated the intellectual contents. All authors participated in preparing the final draft of the manuscript, revised the manuscript and critically evaluated the intellectual contents. All authors have read and approved the content of the manuscript and confirmed the accuracy or integrity of any part of the work.
Competing interests

The authors declare that they have no competing interests.

Ethical considerations

Ethical issues (including plagiarism, data fabrication, double publication) have been completely observed by the authors.

Funding/Support

None.

References

1. Martín-Cleary C, Ortiz A. CKD hotspots around the world: where, why and what the lessons are. A CKJ review series. Clin Kidney J. 2014;7:519-23 doi: 10.1093/ckj/sfu118.

2. Rajapurkar MM, John GT, Kirpalani AL, Abraham G, Agarwal SK, Almeida AF et al. What do we know about chronic kidney disease in India: first report of the Indian CKD registry. BMC Nephrol. 2012;13:10. doi: 10.1186/1471-2369-13-10.

3. Jha V, Garcia-Garcia G, Iseki K, Li Z, Naicker S, Plattner $B$, et al. Chronic kidney disease: global dimension and perspectives. Lancet. 2013;382:260-72. doi: 10.1016/S01406736(13)60687-X.

4. World Health Organization.Interna-tional Expert Consultation on Chronic Kidney Disease of UnknownEtiology. Colombo, Sri Lanka; 2016. https://apps.who.int/iris/handle/10665/255137. Accessed 25 April 2020.

5. Kidney Disease: Improving Global Outcomes (KDIGO) CKD Work Group. KDIGO 2012 Clinical Practice Guideline for the Evaluation and Management of Chronic Kidney Disease. Kidney Int Suppl. 2013;3:1-150

6. District Census Handbook (DCHB) 2011 GOI (2011). https:// censusindia.gov.in/2011census/dchb/DCHB.html. Retrieved 08 August 2019

7. Gifford FJ, Gifford RM, Eddleston M, Dhaun N. Endemic Nephropathy Around the World. Kidney Int Rep. 2017;2:28292. doi: 10.1016/j.ekir.2016.11.003.

8. Tatapudi RR, Rentala S, Gullipalli P, Komarraju AL, Singh AK, Tatapudi VS, et al. High prevalence of CKD of unknown etiology in Uddanam, India. Kidney Int Rep. 2018;4:380-9. doi: 10.1016/j.ekir.2018.10.006.

9. Almaguer M, Herrera R, Orantes CM. Chronic kidney disease of unknown etiology in agricultural communities. MEDICC Rev. 2014;16:9-15.

10. Pearce N, Caplin B, Gunawardena N, Kaur P, O'CallaghanGordo C, Ruwanpathirana T. CKD of Unknown Cause: A Global Epidemic? Kidney Int Rep. 2018;4:367-9. doi: 10.1016/j.ekir.2018.11.019.

11. Weaver VM, Fadrowski JJ, Jaar BG. Global dimensions of chronic kidney disease of unknown etiology (CKDu): a modern era environmental and/or occupational nephropathy? BMC Nephrol. 2015;16:145. doi: 10.1186/s12882-015-0105-6. 